\title{
Photo activated disinfection efficiency of low-intensity laser and comprehensive prevention of caries and gingivitis in adolescents using bracket system
}

\author{
Dmitry Ye. Suetenkov, Anna P. Petrova* \\ and Tatyana L. Kharitonova \\ V. I. Razumovsky Saratov State Medical University \\ 410012, Russia \\ *anna_petrova76@mail.ru
}

Received 27 February 2014

Accepted 14 April 2014

Published 3 June 2014

\begin{abstract}
It is very important to study the problem of caries and gingivitis in adolescents who are being treated for orthodontic pathology with bracket systems. The method of combined treatment which incorporates the use of medicine and laser therapy has been proved effective in caries prevention. This research aims to study clinical aspects of the effectiveness of the combined influence of the low-intensity laser "OPTODAN" with a wavelength of $0.85 \mu \mathrm{m}$ (Scientific Development and Production Center "VEND", Saratov, Russia) in carries prevention. The research also aims to study the disinfection method of PAD with "FotoSan" ("CMS Dental", Denmark, with a wavelength of $625-635 \mathrm{~nm}$, where toluidine blue is used as photosensitizer molecules) combined with regular measure to prevent gingivitis in adolescents being treated for orthodontic pathology with bracket systems. This paper presents the results of 1.5 years of clinical study of 60 12-13-year-old children. They were examined before and after the orthodontic treatment: their decayed, missing, filled teeth (DMFT), decayed, missing, filled tooth surfaces (DMFS) index and hygiene status (OHI-S) were calculated, gum inflammations were detected. Before the orthodontic treatment, their mouths were sanitized. After orthodontic appliances were placed, the children were randomly divided into two groups of 30 each. Children of the first group, while being treated with braces, took traditional preventative measures against gum inflammation and caries: occupational hygiene, local antiseptics $(0.05 \%$ chlorhexidine solution $)$, the use of remineralizing and phosphorus containing applications four times a year. The children of the second group, along with the traditional scheme of preventive measures, were treated with the devices "FotoSan" and "Optodan". Results of clinical examination of the second group have accurately proved decrease in the growth of dental caries intensity and surface caries intensity $(\triangle \mathrm{DMFT}$, $\triangle \mathrm{DMFS}$ ) and in gingivitis level at the end of the orthodontic treatment. So the results of our clinical research have proved the effectiveness of laser therapy and comprehensive prevention of caries and gingivitis in adolescents using bracket system.
\end{abstract}

Keywords: Children; orthodontic treatment; laser; caries; gingivitis prophylaxis.

This is an Open Access article published by World Scientific Publishing Company. It is distributed under the terms of the Creative Commons Attribution 3.0 (CC-BY) License. Further distribution of this work is permitted, provided the original work is properly cited. 


\section{Introduction}

Epidemiological indicators and data presented in various theoretical sources suggest a high intensity of caries in the course of treatment with braces. ${ }^{1}$ The prevalence of dental caries in children undergoing treatment with permanent equipment was significantly higher than in healthy children without malocclusion. ${ }^{2}$

Caries is mainly caused by acids produced by plaque microorganisms due to consumption of carbohydrates. Acid causes the initial stages of an inorganic enamel decalcification, and then the disintegration of the organic matrix. Children's organs and tissues are in a state of functional development. When permanent teeth initially appear, they are characterized by low mineral maturity of hard tissues. Final mineralization occurs in $2-4$ years, cervical zones and fissures get mineralized within 5-6 years. Abnormal teething and malocclusion are the causes of increased susceptibility of hard tissues to caries. During the placement of the brackets and later when they are used, there is a significant risk of caries around the bracket, especially in the cervical area. . $^{3,4}$ It arises due to the fact that the cervical area is the principal area of nonmineralized dental plaque accumulation on the crown of the tooth and area of incomplete mineralization.

There is a need for preventive measures at an early age, especially when a child undergoes an orthodontic treatment. ${ }^{5-7}$

In the treatment with bracket systems, there is also the risk of inflammation of the gums. ${ }^{8}$ This is because of the complex processes of teeth movement and rearrangement of periodontal tissue which takes place against the background of the immaturity of child's marginal periodontium. At the same time, microbial contamination ${ }^{9}$ is a leading etiological factor in the development of gingivitis. Tooth-jaw system pathology and fixed orthodontic appliances make the situation with the microbial contamination even worse.

Thus, the Rey measures to prevent marginal periodontal inflammatory diseases and dental caries in children's teeth with a bracket system is microbial decontamination, which includes patient's motivation, correction of personal hygiene, occupational health and the use of antiseptic remineralizing funds. ${ }^{10-12}$ But despite the ongoing activities, the intensity of caries and marginal periodontal inflammation in children with braces continues to remain at a high level. In this regard, it is apparent that there is a need to search for new combined methods to solve this problem, including the use of lasers. ${ }^{13,14}$

Thanks to the development of special soft lasers, which do not heat the tissues in their impact, and development of nontoxic medicine, which can get accumulated in the membranes of abnormal cells and release oxygen under the influence of laser light, it has become possible to use photo activated disinfection (PAD) in the treatment of already existing periodontal disease ${ }^{15}$ and to use this method to prevent inflammatory processes. ${ }^{16}$

The disinfection method of PAD "FotoSan" ("CMS Dental", Denmark) is based on the application of laser with a wavelength of $625-635 \mathrm{~nm}$ and photosensitizer molecules which can move in triple state under the influence of light in the visible part of the spectrum and after the return to the main state pass the energy to other compounds.

Mechanism of the action against caries during laser light on the tooth enamel in the aspect of quantum theories of chemical bonds is based on the effect of photon on enamel crystal structures. ${ }^{17}$ When exposed to laser light, the permeability of teeth and enamel solubility decrease, processes get accelerated, the remineralization of enamel microhardness increases, the effectiveness of anti-caries funds ${ }^{18}$ increases as well.

The laser light works in two ways: directly on the enamel of the tooth pulp which, in general, produces an integrated effect (higher tooth resistance to tooth decay in the course of preventative measures and the disappearance of the chalk stains on enamel in the course of treatment). In addition, the laser light inactivates Streptococcus mutans, which many researchers ${ }^{19-22}$ consider as one of the leading microbial factors in the pathogenesis of caries. Lowintensive laser device "OPTODAN" ("VEND", Saratov, Russia) with semiconductor emitter, generates pulsed light (wave length of $0.85 \mu \mathrm{m}$, with the frequency: mode $\mathrm{Hz}$, mode 2: $2000-3000 \mathrm{~Hz}$, pulse power $5 \mathrm{~W}$ ). It is intended for use in the workplace of the d1: 80-100 entist.

However, as far as we are concerned there are no research papers on traditional methods combined with the impact of lasers with different wavelengths to achieve greater efficiency in the prevention of dental caries and gingivitis in adolescents with braces. The research aims to study clinical aspects of the effectiveness of the combined influence of the lowintensity laser "OPTODAN" with a wavelength of 
$0.85 \mu \mathrm{m}$ (Scientific Development and Production Center "VEND", Saratov, Russia) in carries prevention. The research also aims to study the disinfection method of PAD with "FotoSan" ("CMS Dental", Denmark, with a wavelength of 625$635 \mathrm{~nm}$, where toluidine blue is used as photosensitizer molecules) combined with regular measure to prevent gingivitis in adolescents who are being treated for orthodontic pathology with bracket systems.

\section{Materials and Methods}

\subsection{The selection of test subjects (participants)}

We studied cases of sixty 12-13-year-old children who were being treated with metal bracket systems at the University Clinic of Pediatric Dentistry, V. I. Razumovsky Saratov State Medical University. Their average age was $12.78 \pm 0.17$. Twenty patients were girls $(33.34 \%)$ and $40(66.66 \%)$ were boys. We selected healthy children without the accompanying pathology of the organs and systems of the body. We tested their oral cavities before and after the orthodontic treatment and registered caries intensity status. In the course of the research, we did not violate medical ethics. Testing methods and methods of treatment had been previously approved by Ethics Committee of V. I. Razumovsky Saratov State Medical University. Parents of the selected children were duly informed about the upcoming research and they confirmed their agreement in a written form before the treatment started.

\subsection{Methods}

\subsubsection{Thorough detection of Caries}

We thoroughly inspected the teeth visually which is the main research method. ${ }^{23,24}$ To detect hidden areas of enamel demineralization we used the method of drying. The method is based on the modification of the index of light refraction in the area of enamel demineralization. Selected teeth were cleaned from the dental plaque and were dried with air flow within $5 \mathrm{~s}$. Areas of enamel demineralization turned into bleak chalk-like color. We also used the method of reflection which allows to detect the initial stage of caries with the help of the reflected light of the lamp of the dental treatment unit. Destructive caries was diagnosed with the help of the periodontal probing method. Here are some additional methods: the method of vital coloring of teeth with largemolecule substances $(2 \%$ hydrous solution of Methyleni coerulei) and X-ray tests. We were able to diagnose caries cavities and clinically detectable areas of demineralization, ${ }^{25}$ which were chosen as diagnostics levels. Then we calculated child's caries intensity index: decayed, missing, filled teeth (DMFT) and decayed, missing, filled tooth surfaces (DMFS)-indexes. DMFT is a count of the number of decayed, missing, filled tooth in a person's mouth. DMFS is a count of the number of decayed, missing, filled teeth surfaces in a person's mouth.

\subsubsection{Determination of hygiene status}

To determine the amount of plaque on permanent teeth, the hygiene index of J. C. Green, J. R. Vermillion OHI-S (1964) was used. The simplified oral hygiene index (OHI-S) uses the method of selecting the surfaces to be scored, thus the scores, enabling to be obtained. The OHI-S has two components, the Debris Index and the Calculus Index. Each of these indexes, in turn, is based on numerical determinations representing the amount of debris or calculus found on the preselected tooth surfaces. The six surfaces examined for the OHI-S are selected from four posterior and two anterior teeth. The criteria for classifying debris and calculus is shown in Tables 1 and 2.

After the scores for debris and calculus are recorded, the Index values are calculated. For each individual, the debris scores are totaled and divided by the number of surfaces scored. At least two of the six possible surfaces must be examined for an individual score to be calculated. After that the score for a group of individuals is obtained by computing the average of the individual scores. The average

Table 1. Criteria for classifying debris.

\begin{tabular}{ll}
\hline Scores & Criteria \\
\hline 0 & No debris or stain present. \\
1 & Soft debris covering not more than one third of the \\
& tooth surface, or presence of extrinsic stains \\
& without other debris regardless of surface area \\
& covered. \\
& Soft debris covering more than one third, but not \\
2 & more than two thirds, of the exposed tooth surface. \\
& Soft debris covering more than two thirds of the \\
& exposed tooth surface.
\end{tabular}


Table 2. Criteria for classifying calculus.

\begin{tabular}{ll}
\hline Scores & \multicolumn{1}{c}{ Criteria } \\
\hline 0 & No calculus present. \\
1 & $\begin{array}{l}\text { Supragingival calculus covering not more than third } \\
\text { of the exposed tooth surface. }\end{array}$ \\
2 & $\begin{array}{l}\text { Supragingival calculus covering more than one third } \\
\text { but not more than two thirds of the exposed tooth } \\
\text { surface or the presence of individual flecks of } \\
\text { subgingival calculus around the cervical portion of } \\
\text { the tooth or both. }\end{array}$ \\
& $\begin{array}{l}\text { Supragingival calculus covering more than two third } \\
\text { of the exposed tooth surface or a continuos heavy } \\
\text { band of subgingival calculus around the cervical } \\
\text { portion of the tooth or both. }\end{array}$ \\
&
\end{tabular}

individual or group score is known as the simplified debris index (DI-S).

The same methods are used to obtain the calculus scores or the simplified calculus index (CI-S).

The average individual or group debris and calculus scores are combined to obtain the OHI-S.

The CI-S and DI-S values may range from 0 to 3 ; the OHI-S values range from 0 to 6 .

Debris Index

$$
\begin{aligned}
& \text { (The buccal - scores) } \\
& =\frac{+(\text { The lingual }- \text { scores })}{(\text { Total number of examined buccal }} .
\end{aligned}
$$

Calculus Index

$$
\begin{gathered}
=\frac{(\text { The buccal }- \text { scores })}{+(\text { The lingual }- \text { scores })} \\
\quad \begin{array}{c}
\text { (Total number of examined buccal } \\
\wedge \text { lingual surfaces })
\end{array} \\
\text { Oral Hygiene Index } \\
=\text { Debris Index }+ \text { Calculus Index. }
\end{gathered}
$$

Scoring: 0 scores - excellent, $0.1-0.9-\operatorname{good}, 1.0-$ 1.9 - fair, $2.0-3.0$ - poor.

\subsubsection{Determination of marginal period- ontium condition}

The presence and intensity of inflammation of the gums were assessed using the papillary marginal attached (PMA) Index modified by Parma (1960). PMA allows to judge about the extent and severity of gingivitis. The index can be expressed in absolute terms or as a percentage.

Assessment of the inflammatory process is conducted in the following ways:

inflammation of the papilla -1 point;

inflammation of the gingiva -2 points;

alveolar inflammation of the gums -3 points.

Each tooth's gum condition is evaluated separately.

The index is calculated with the following formula (where the 3 - averaging factor):

$$
\mathrm{PMA}=\frac{\sum \text { figures } \in \text { points } x 100}{3 x \text { the number of teeth } \in \text { the subject }} .
$$

The number of teeth in the dentition depends on the age of the subject: $6-11$ years -24 teeth, $12-14$ years -28 teeth, 15 years and older -30 teeth. If there are missing teeth, only actual count is taken into consideration.

The value of the index at a limited prevalence of pathological process reaches $25 \%$. When pathological process is intense, the indicators approach $50 \%$, and for the further spread of the pathological process and increase of its severity, it is $51 \%$ or more.

At the heart of the PMA index lies SchillerPisarev (ingredients of Schiller-Pisarev: solution of $1 \mathrm{~g}$ crystal iodine, $2 \mathrm{~g}$ potassium iodide and $40 \mathrm{~mL}$ distillate water), which is based on the identification of glycogen in the gums, the content of which increases sharply during inflammation due to lack of keratinization in the epithelium. In the epithelium of healthy gums, glycogen is either absent or hardly detectable. Depending on the intensity of the color of gum inflammation modified by lubrication solution, Schiller-Pisarev varies from light brown to dark brown in color. In the case of healthy periodontal, the difference in the color is not detected. The sample can also serve as a criterion for the effectiveness of the treatment, as antiinflammatory therapy reduces the amount of glycogen in the gums.

To characterize inflammation, we use the following gradation:

staining of the gum in a straw-yellow color - a negative test;

staining of the mucosa in a light brown color weakly positive sample;

staining in a dark brown color — positive test. 
Clinical and paraclinical examination of children's dental status was carried out before and after orthodontic treatment with the help of the same methods.

\subsection{The experimental techniques}

The study was simultaneously conducted in two groups. The results of experimental group (2nd group) were compared with the results of control group (first group). Children undergoing treatment were randomly divided into two groups of 30 each. Both groups correlated in age and sex. Children of the first group, while being treated with braces, took traditional preventative measures against gum inflammation and caries. The second group consisted of children whose treatment with the bracket system and preventative measures were supplemented with laser devices ("FotoSan" ("CMS Dental", Denmark) and low intensive laser "OPTODAN" ("VEND", Russia)) in addition to the traditional scheme. $100 \%$ of participants were regularly tested.

Before the beginning of the dynamic monitoring and fixing of orthodontic appliances, children's mouths were sanitized. The first group of children took traditional preventative measures: local prevention of dental caries and gingivitis with the help of oral hygiene through single-stages occupational hygiene, local antiseptics $(0.05 \%$ chlorhexidine for rinsing twice a day) for 10 days, use of calcium and phosphorus contaning gel (ROCS Medical Minerals, "DRC"). Applications of remineralization were carried out daily after brushing teeth before going to bed within 10 days. This course of preventative measures was taken four times a year. The final stage of each course was the use of fluoride in the form of gel. The hygiene products have been recommended for children with fluoride. Both groups used a aminofluoride-containing toothpaste (concentration of ions of fluorine - 1400 parts-per-million; ppm).

The children of the 2nd group, along with the traditional scheme of preventive measures used the devices "FotoSan" and "OPTODAN".

Prevention of gingivitis using "FotoSan" $(630 \mathrm{~nm}$ wavelength, power of $0.4 \mathrm{~W}$ with segmental features in 4 segments (2 upper and 2 lower) using the rounded nozzles according to the measures is shown in Fig. $1^{26,27}$ :

(1) After the professional oral hygiene, low-intensive laser with the same characteristics was used

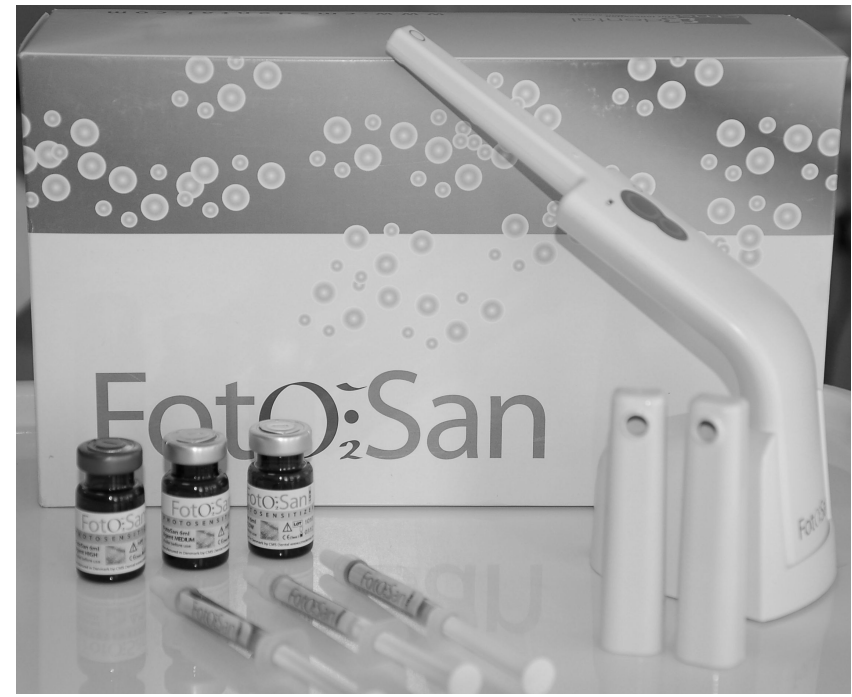

Fig. 1. Complex "FotoSan".

but in combination with the Toluidine blue as a photosensibilizer (Toluidine blue (Toluidine Blue $\mathrm{O}$ ) on the mucous membranes of the oral cavity for 5-7 min (Fig. 2)). Toluidine blue or tolonium chloride upon contact with the tissues of the tooth is fixed to the membranes of bacteria selectively, by recognizing them as targets. It is activated only in the presence of a certain wavelength of laser light and is harmless to the cells of body tissues and does not cause allergy. ${ }^{28}$

(2) Removal of excess by rinsing the mouth.

(3) The glare of each segment was carried out for $10 \mathrm{~s}$ (Fig. 3).

A course of treatments was four procedures per year with three months apart. Prevention of dental caries was done with the help of infrared laser therapy "OPTODAN" (Fig. 4) (0.98-0.85 $\mu \mathrm{m}$ wavelength, 0.5 power $-1.0 \mathrm{~W}, 2000 \mathrm{~Hz}$ ) after

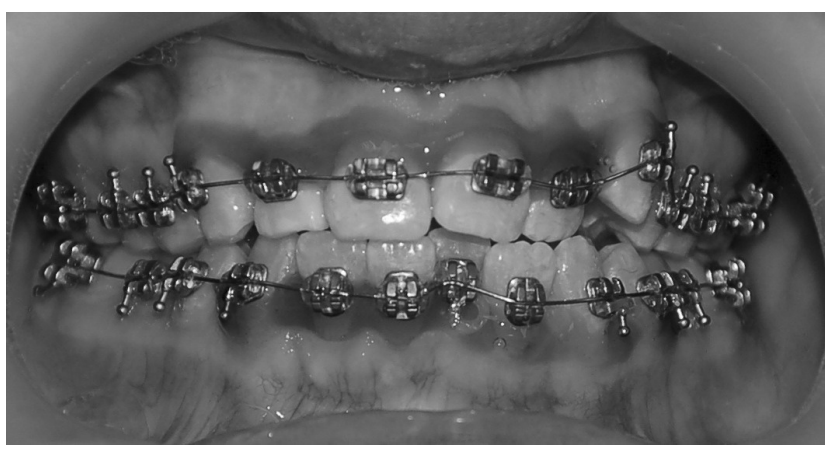

Fig. 2. The application of the photosensitizer on the mucous membrane of marginal periodontal tissue. 


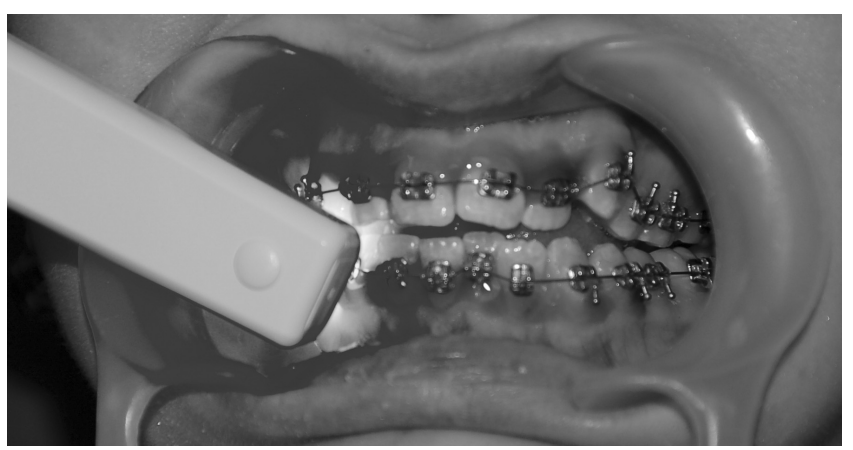

Fig. 3. The laser action of "FotoSan" after tha application of the photosensitizer.

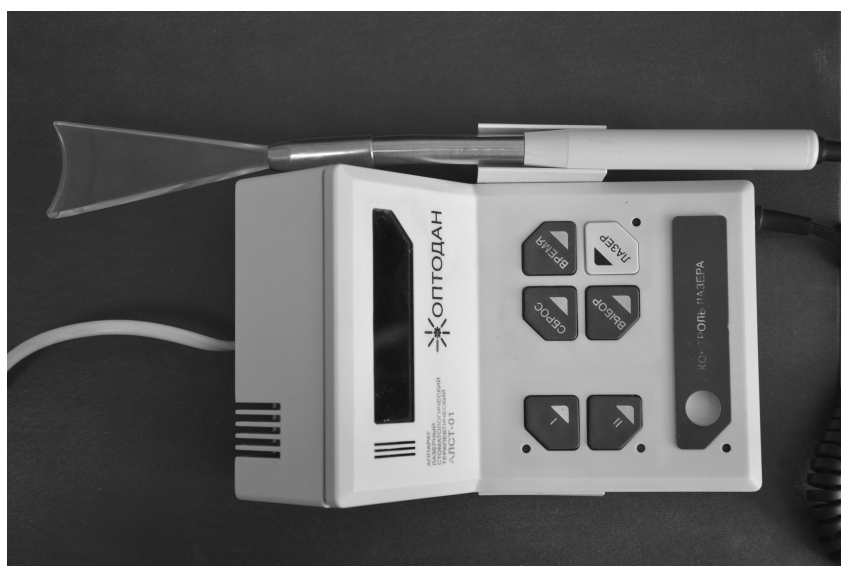

Fig. 4. "Optodan" device.

professional oral care. We used the method of surface radiation with periodontal nozzles. Area of exposure includes two segments (upper and lower teeth alignments), 2 min for each segment for the total course of 10 procedures (daily) is recommended. Four courses per year with three months apart are recommended.

\section{Results}

The results of the undertaken preventative measures were assessed in both groups $(1$ - traditional treatment, 2 - combined treatment with the use of laser therapy) at the end of the orthodontic treatment after brackets had been removed (see Tables 3-5). Then the results were compared with the results of the complex dental examination undertaken before the beginning of the orthodontic treatment. Working with numerical results and statistics, we calculated arithmetic middling $(M)$ and errors $(m)$. To assess the accuracy of the difference in the average data we used Student's $t$-test.
Table 3. Values of the dental indices in the first group before and after treatment $(n=30)$.

\begin{tabular}{lccc}
\hline Index & $\begin{array}{c}\text { Before treatment, After treatment, } \\
\mathrm{M} \pm \mathrm{m}\end{array}$ & $\mathrm{M} \pm \mathrm{m}$ & $\begin{array}{c}\text { The significance } \\
\text { of differences }\end{array}$ \\
\hline PMA, \% & $46.3 \pm 1.97$ & $29.76 \pm 0.94$ & $<0.001$ \\
OHI-S & $1.79 \pm 0.05$ & $0.61 \pm 0.07$ & $<0.001$ \\
\hline
\end{tabular}

Table 4. Values of the dental indices in the second group before and after treatment $(n=30)$.

\begin{tabular}{lccc}
\hline Index & $\begin{array}{c}\text { Before treatment, After treatment, } \\
\mathrm{M} \pm \mathrm{m}\end{array}$ & $\mathrm{M} \pm \mathrm{m}$ & $\begin{array}{c}\text { The significance } \\
\text { of differences }\end{array}$ \\
\hline PMA, \% & $49.1 \pm 1.01$ & $27.34 \pm 0.65$ & $<0.001$ \\
OHI-S & $1.67 \pm 0.04$ & $0.57 \pm 0.04$ & $<0.001$ \\
\hline
\end{tabular}

Statistics were calculated with the help of Excel 2000 (Microsoft Inc., 1999), Statistica for Windows, v. 5.0 (Stat Soft Inc., 1995).

Complex estimation of dental status in children before the orthodontic treatment allowed to assess hygienic mouth cavity condition before treatment (an approximate value of the hygiene index OHI-S was $1.79 \pm 0.05$ in the first group and $1.67 \pm 0.04$ in the second group), caries intensity in teeth (DMFT index was $1.33 \pm 0.09$ in average in the first group and $2.49 \pm 0.28$ in the second group) and surfaces (DMFS index was $3.33 \pm 0.17$ in average in the first group and $3.76 \pm 0.33$ in the second group). Estimation of a periodontal/gingival marginalis tissue condition in children showed PMA (in Parma modification) values being $46.3 \pm 1.97$ in the first group and $49.1 \pm 1.01$ in the second group, that corresponded to periodontal inflammation of the moderate degree.

After the orthodontic treatment was completed, positive dynamics of hygienic indices OHI-S and PMA (in Parma modification) was observed in both groups with a high degree of the significance of differences/reliability (the average values of the hygiene index OHI-S were $0.61 \pm 0.07$ and $0.57 \pm 0.04$ in the first and in the second group, respectively, and those of PMA index (in Parma modification) were $29.76 \pm 0.94$ in the first group and $27.34 \pm 0.65$ in the second, that corresponded to periodontal inflammation of the mild degree). At the same time, reliably lower values of these indices were recorded in the second group in comparison with the first one. However, in both groups of children, caries intensity 
Table 5. Comparative values of DMFT and DMFS indices and growth of those indices in both groups before and after orthodontic treatment.

\begin{tabular}{|c|c|c|c|c|c|}
\hline \multirow[b]{2}{*}{ Groups under study } & \multirow[b]{2}{*}{ Period of study } & \multicolumn{2}{|c|}{$\begin{array}{l}\text { Values of teeth caries intensity, } \\
\qquad \mathrm{M} \pm \mathrm{m}\end{array}$} & \multicolumn{2}{|c|}{$\begin{array}{l}\text { Growth of intensity, } \\
\qquad \mathrm{M} \pm \mathrm{m}\end{array}$} \\
\hline & & DMFT & DMFS & DMFT & DMFS \\
\hline \multirow[t]{2}{*}{$\begin{array}{l}\text { The 1st group } \\
\qquad(n=30)\end{array}$} & $\begin{array}{l}\text { Before fixing } \\
\text { braces }\end{array}$ & $1.33 \pm 0.09$ & $3.33 \pm 0.17$ & $2.77 \pm 0.56$ & $2.66 \pm 0.30$ \\
\hline & $\begin{array}{c}\text { After removing } \\
\text { braces }\end{array}$ & $4.10 \pm 0.14$ & $5.99 \pm 0.19$ & & \\
\hline \multicolumn{2}{|c|}{ The significance of differences in the group } & $p<001$ & $p<0.001$ & & \\
\hline \multirow[t]{2}{*}{$\begin{array}{l}\text { The second group } \\
\quad(n=30)\end{array}$} & $\begin{array}{l}\text { Before fixing } \\
\text { braces }\end{array}$ & $2.49 \pm 0.28$ & $3.76 \pm 0.33$ & $1.05 \pm 0.14$ & $1.37 \pm 0.13$ \\
\hline & $\begin{array}{c}\text { After removing } \\
\text { braces }\end{array}$ & $3.54 \pm 0.21$ & $5.13 \pm 0.15$ & & \\
\hline \multicolumn{2}{|c|}{ The significance of differences in the group } & $p<0.01$ & $p<0.001$ & & \\
\hline \multicolumn{4}{|c|}{ The significance of differences between the groups } & $p<0.001$ & $p<0.001$ \\
\hline
\end{tabular}

in teeth and in surfaces had grown (average DMFT index in the first group was $4.10 \pm 0.14$ and $3.54 \pm$ 0.21 in the second group; average DMFS index in the first group was $5.99 \pm 0.19$ and $5.13 \pm 0.15$ in the second group). The growth of caries intensity and surface caries intensity in the first group was $2.77 \pm 0.56$ and $2.66 \pm 0.30$ correspondingly, for the second group the result was $1.13 \pm 0.14$ and $1.35 \pm$ 0.13 correspondingly.

\section{Discussion}

There is a high risk of dental caries and gingivitis in the course of the orthodontic treatment for 12-yearold children because of the nonremovable orthodontic appliances which make it difficult to take proper hygienic care of teeth. At the same time, at this age children are still in the process of physiological development of parodontium and hard tissues. Taking all these factors into account, we may conclude that it is very important to study the preventative measures. Traditional preventative measures approved by the Russian National Committee of Pediatric Dentistry include the use of the following: $0.05 \%$ chlorhexidine solution, remineralizing and phosphorus containing medicine, aminofluoridecontaining toothpaste. Combined methods of treatment (the use of medicine and laser therapy) have become very popular now because of their effectiveness, painlessness and absence of any side effects. Though it should be mentioned that previously these methods were studied separately concerning preventative measures only for one of the main dental diseases.

We have studied clinical effectiveness of the combined treatment with the help of "OPTODAN" ("VEND", Russia) and "FotoSan" ("CMS Dental", Denmark) in addition to traditional preventative measures for caries and gingivitis in adolescents who are being treated for orthodontic pathology with bracket systems. The initial level of hygiene of the first group was $1.79 \pm 0.05$, the initial level of hygiene of the second group was $1.67 \pm 0.04$, which equals satisfactory level of hygiene. After the treatment, the hygiene index became lower in both groups: first group $=0.61 \pm 0.07$, second group $=0.57 \pm 0.04$. At the same time, we should keep in mind that the decrease could have been influenced by intensive medical preventative measures, laser therapy, improved hygienic care and other factors.

The results of our clinical research show that before the treatment there was a medium degree of severity of gingivitis. In the first group it was $46.3 \pm 1.97$, in the second group it was $49.1 \pm 1.01$. After the treatment, the indicator for the first group became lower $(29.76 \pm 0.94)$ and for the second group it was $27.34 \pm 0.65$ which corresponds to a 
mild degree of gingivitis. We have noticed that in spite of the fact that before the treatment there was a much higher level of the inflammation of marginal periodontal tissue in the second group $(49.1 \pm 1.01)$ in comparison with the first group $(46.3 \pm 1.97)$, after the treatment the level of the inflammation in the second group objectively became lower $(27.34 \pm 0.65)$ than in the first group $(29.76 \pm 0.94$, $p<0.001)$.

More sufficient reduction of gingivitis degree in the second group can be explained by the fact that the ability of a photosensitizer to be stored in cells showing energy deficiency (damaged or bacterial) allows to destroy them without any pathogenic effect on healthy cells. ${ }^{29-31}$ As a result of the photodynamic reaction, not only destruction of pathogenic microflora in the periodontal tissues occurs, but also a photocoagulating film is formed on the surface of gingiva, which protects these tissues from repetitive invasion of pathogenic microorganisms. It is essential not only for reduction of the inflammation intensity, but also for keeping the periodontal tissue intact in the initial condition. Besides, PAD increases capillary blood stream that is the evidence of normalization of periodontal tissue trophism which in its turn increases an oxygenation level of the periodontal tissue and normalizes oxygenic metabolism in the tissues.

The analysis of dental caries intensity shows that before the treatment the DMFT intensity in the first and second groups was $1.33 \pm 0.09$ and $2.49 \pm 0.28$, correspondingly. According to WHO experts (1980), it corresponds to a low level of caries intensity. After the orthodontic treatment, the DMFT index in the first group became $4.1 \pm 0.14$ and in the second group the index number became $3.54 \pm 0.21$. According to WHO experts (1980), it corresponds to a moderate level of caries intensity. Before the treatment, the DMFS index in both groups was $3.33 \pm 0.17$ and $3.76 \pm 0.33$, correspondingly. After the treatment, the index number in the first group became $5.99 \pm 0.19$ and in the second group it became $5.13 \pm 0.15$. So the level of caries intensity increased in both groups. It happened despite the fact that hygiene level had become much better in both groups (from $1.79 \pm 0.05$ to $0.61 \pm 0.07(p<0.001)$ in the first group and from $1.67 \pm 0.04$ to $0.57 \pm 0.04$ in the second group $(p<0.001))$. Despite the increase in dental and surface caries intensity index after the treatment, the index of the growth of dental and surface caries intensity $(\triangle \mathrm{DMFT}, \triangle \mathrm{DMFS})$ in second group was objectively lower than $1.05 \pm 0.14$ and $1.37 \pm 0.13$ correspondingly in comparison with the index of the growth of dental and surface caries intensity in first group $(2.77 \pm 0.56$ and $2.66 \pm 0.30$ correspondingly $(p<0.001))$. We assume that the decrease in dental and surface caries intensity is due to the lowintensity lazar irradiation used in addition to traditional preventative measures. ${ }^{32,33}$

Low-intensive laser radiation of the "OPTODAN" device, which statically influences caries, provides high mineralization of hard tissues and resistance to factors causing caries. The mechanism of anticaries effect of the "OPTODAN" device is based on the influence of photons generated by the laser source on the tooth enamel which causes complex associated changes in the crystal structure, namely, packing of the enamel crystal lettuce, decreasing of its solubility, that results in increasing of its resistance to caries. Due to stimulation of the microcirculation, a secretary function of odontoblasts is activated in the pulp which leads to forming of the irregular dentine and intensifying of metabolic processes in tooth tissue in general. At the same time, specific humoral immune mechanisms and stimulation of nonspecific protective mechanisms are activated, that cause strengthening of local immunological mechanisms of protection. The clinical data obtained are evidence of high therapeutic and prophylactic effect of the combined method using traditional preventive measures and laser radiation of different action spectrum for caries and gingivitis prophylaxis in teenagers who are being treated with nonremovable orthodontic appliances.

\section{Conclusion}

Taking all these factors into account, we can conclude that the combined influence of low-intensity irradiation of lazars "OPTODAN" and "FotoSan" in addition to traditional preventative measures has proved to be most effective in the prevention of caries and gingivitis in 12-year-old children who are being treated with nonremovable orthodontic appliances. The results concerning gingivitis are the best. The results concerning caries indicate only the decrease in the intensity level. So we will continue to search for a solution to this problem. 


\section{References}

1. N. L. Ramm, N. V. Ozhgihina, E. S. Sorokina, "Demineralization of enamel and dental caries as a complication of orthodontic treatment using permanent orthodontic equipment," Modern Orthodontics 27, 20-22 (2012).

2. P. S. Fleece, L. A. Khomenko, I. L. Skrypnyk, T. A. Shuminskaya, "Prevalence of focal enamel demineralization in patients in the dynamics of orthodontic treatment," Orthodontics 33, 86 (2006).

3. S. O. Vital, C. Haignere-Rubinstein, J.-J. Lasfargues, C. Chaussain, "Caries risk and orthodontic treatment," Int. Orthodontics 8, 28-45 (2010).

4. M. Karadas, K. Cantekin, M. Celikoglu, "Effects of orthodontic treatment with a fixed appliance on the caries experience of patients with high and low risk of caries," J. Dent. Sci. 6, 195-199 (2011).

5. T. G. Zakalata, A. I. Popov, "Prevention of demineralization in children with orthodontic treatment equipment," Modern Orthodontics 27, 23-24 (2012).

6. P. V. M. Alves, W. S. Alviano, A. M. Bolognese, L. I. Nojima, "Treatment protocol to control Streptococcus mutans level in an orthodontic patient with high caries risk," Am. J. Orthod. Dentofacial Orthop. 133, 91-94 (2008).

7. M. A. Robertson, Ch. How Kau, J. D. English, R. P. Lee, J. Powers, J. T. Nguyen, "MI paste plus to prevent demineralization in orthodontic patients: A prospective randomized controlled trial," Am. J. Orthod. Dentofacial Orthop. 140, 660-668 (2011).

8. V. Krishnan, R. Ambili, Z. Davidovitch, N. C. Murphy, "Gingiva and orthodontic treatment," Semin. Orthod. 13, 257-271 (2007).

9. W. Barnabé, T. de Mendonça-Neto, F. C. Pimenta, L. F. Pegoraro, J. M. Scolaro, "Efficacy of sodium hypochlorite and coconut soap used as disinfecting agents in the reduction of denture stomatitis, Streptococcus mutans and Candida albicans," J. Oral Rehabil. 31, 453-459 (2004).

10. F. B. Zanatta, C. H. C. Moreira, C. K. Rösing, "Association between dental floss use and gingival conditions in orthodontic patients," Am. J. Orthod. Dentofacial Orthop. 140, 812-821 (2011).

11. N. Pahwa, A. Kumar, S. Gupta, "Short term clinical effectiveness of a $0.07 \%$ cetylpyridinium chloride mouth rinse in patients undergoing fixed orthodontic appliance treatment," The Saudi Dent. J. 23, 135-141 (2011).

12. M. Klukowska, A. Bader, Ch. Erbe, Ph. Bellamy, D. J. White, M. K. Anastasia, H. Wehrbein, "Plaque levels of patients with fixed orthodontic appliances measured by digital plaque image analysis," Am. J. Orthod. Dentofacial Orthop. 139, e463-e470 (2011).
13. S. A. Naumovich, A. V. Jars, A. P. Dmitrochenko, A. N. Dosta, A. P. Pashuk, "Application of laser technology in dentistry," J. Mod. Stomatol. 1, 4-13 (2006).

14. K. Konopka, T. Goslinsk, "Photodynamic therapy in dentistry," J. Dent. Res. 86, 694-707 (2007).

15. E. A. Genina, V. A. Titorenko, G. V. Simonenko A. N. Bashkatov, G. M. Shub, A. B. Lepilin, V. V. Tuchin, I. V. Yaroslavsky, G. B. Altshuler, "Phototherapy of gingivitis: Pilot clinical study," J. Innov. Opt. Health Sci. 4, 437-446 (2011).

16. E. G. de Oliveira Mima, A. C. Pavarina, M. M. Silva, D. G. Ribeiro, C. E. Vergani, C. Kurachi, V. S. Bagnato, "Denture stomatitis been pre-treated with photodynamic therapy: Five cases," Oral Surg. Oral Med. Oral Pathol. Oral Radiol. Endod. 112, 602-608 (2011).

17. Ch. Kouchaj, "Comparison between a laser fluorescence device and visual examination in the detection of occlusal caries in children," Saudi Dent. J. 24, 169-174 (2012).

18. L. K. A. Rodrigues, M. Nobre dos Santos, D. Pereira, A. Videira, A. V. Pardi, "Carbon dioxide laser in dental caries prevention," J. Dent. 32, 531-540 (2004).

19. R. Fekrazad, F. Khoei, N. Hakimiha, A. Bahador, "Photoelimination of $S$. mutans with two methods of photodynamic and photothermal therapy," Photodiagnosis Photodyn. Ther. 10(4), 626-631 (2013).

20. R. A. Jalil, "Correlating s. mutans counts in saliva with gingival inflammation and amount plaque caries experience in children," J. Dent. Singapore 20, 16-20 (1995).

21. M. ElSalhy, S. Honkala, E. Söderling, A. Varghese, E. Honkala, "Relationship between daily habits, by s. mutans and caries among schoolboys," J. Dent. 41(11), 1000-1006 (2013).

22. J. A. Banas, "Delaying S. mutans colonization in children leads to reduced caries experience," J. Evid. Based Dent. Pract. 13(2), 67-69 (2013).

23. V. Machiulskiene, B. Nyvad, V. Baelum, "A comparison of clinical and radiographic caries diagnoses in posterior teeth of 12-year-old Lithuanian children," Caries Res. 33, 340-348 (1999).

24. B. Nyvad, V. Machiulskiene, V. Baelum, "Reliability of a new caries diagnostic system differentiating between active and inactive caries lesion," Caries Res. 33, 252-260 (1999).

25. R. E. McDonald, D. R. Avery and J. A. Dean, Dentistry for the Child and Adolescence, Mosby, St. Louis, MO (2004), pp. 704.

26. D. Ye. Suetenkov, O. A. Izgaryova, T. L. Kharitonova, E. A. Gritsenko, "The photoactivated disinfection in the complex treatment of dental pathology," Proc. Saratov University, New Series. Series: Physics, Publisher: Saratov State University. 
Named After N. G. Chernyshevsky 13(1), 76-79 (2013).

27. R. F. Donnelly, P. A. McCarron, M. M. Tunney, A. David-Woolfson, "Potential of photodynamic therapy in the treatment of fungal infections of the mouth Design and characterisation of a patch containing mucoadhesive toluidine blue O," J. Photochem. Photobiol. B. Biol. 86, 59-69 (2007).

28. A. Pavlenko, N. Savichuk, V. Peredrii, "Using of photodynamic therapy in patients with generalized periodontitis," Int. Dent. J. 63, 287 (2013).

29. R. F. Donnely, P. A. McCarron, M. M. Tunney "Antifungal photodynamic therapy," Microbiol. Res. 163, 1-12 (2008).

30. T. N. Demidova, M. R. Hamblin, "Effect of cellphotosensitizer binding and cell density on microbial photoinactivation," Antimicrob. Agents Chemother. 49, 2329-2335 (2005).
31. J. Y. Nagata, N. Hioka, E. Kimura, V. R. Batistela, R. S. S. Terada, A. X. Graciano, M. L. Baesso, M. F. Hayacibara, "Antibacterial photodynamic therapy for dental caries: Evaluation of the photosensitizers used and light source properties," Photodiagnosis Photodyn. Ther. 9, 122-131 (2012).

32. A. P. Petrova, D. Y. Suetenkov, A. V. Lepilin, "Effectiveness of differential approach to profilaxis and medical treatment of gastroduodenitis associated patients," Paediatric Dentistry and Dental Profilaxis Journal 3-4, 13-17 (2003).

33. A. P. Korotkova, D. Y. Suetenkov, A. V. Lepilin, E. A. Sirotkin, "Diagnostic value of dental status and electrolite balance among chronic nonspecific gastroduodenitis patients in pediatric," Paediatric Dentistry and Dental Profilaxis Journal 1-2, 40-43 (2002). 